\title{
Spatial variability of soil respiration in a small agricultural watershed - Are patterns of soil redistribution important?
}

\author{
P. Fiener ${ }^{\mathrm{a}, \mathrm{b}, *}$, V. Dlugoß ${ }^{\mathrm{a}}, \mathrm{W}$. Korres ${ }^{\mathrm{a}}$, K. Schneider ${ }^{\mathrm{a}}$ \\ a Geographisches Institut, Universität zu Köln, Albertus Magnus Platz, 50923 Köln, Germany \\ b Indo-German Centre of Sustainability, Indian Institute of Technology Madras, Chennai 600036, India
}

Keywords:

Soil erosion

CO2 efflux

Soil organic carbon

Soil respiration

\begin{abstract}
A B S T R A C T
In terrestrial ecosystems, soil respiration is a key pathway of carbon to the atmosphere. It is highly variable in time and space. Its temporal variability at a single point can be reasonably described by changes in soil temperature and moisture. However, it is much more difficult to determine the drivers of its spatial variability. The aim of this study was to elucidate the interrelationship between the spatial variability of soil respiration and the spatial variability of soil redistribution as well as other soil and crop properties. The study was carried out in a small agricultural watershed ( $4.2 \mathrm{ha}$ ) subjected to water and tillage erosion processes. During three crop cycles (one of sugar beet, two of winter wheat) soil respiration, soil temperature, and soil moisture were measured in situ at least bi-weekly at 20-22 locations. The first stage was to analyse the interrelation of soil temperature as an important control of soil respiration and soil redistribution. In the second stage, measured $\mathrm{CO}_{2}$ effluxes were standardised to $15^{\circ} \mathrm{C}$ and mean fluxes at each location were calculated for the sugar beet year, as well as two growing phases under winter wheat. The mean $\mathrm{CO}_{2}$ effluxes for the five resulting phases at each measuring location were correlated to soil and crop properties and modelled soil redistribution. Moreover, the intercorrelation of all explanatory variables was analysed using principal component analyses, and these principal components were correlated to standardised $\mathrm{CO}_{2}$ effluxes. Except for the second phase in 2009 with combined autotrophic and heterotrophic respiration, which was dominated by root respiration, in all phases there was a tendency that $\mathrm{CO}_{2}$ effluxes at erosional sites were smaller than at depositional sites. The combined analysis of $\mathrm{CO}_{2}$ effluxes, erosion, and other explanatory variables indicates that for heterotrophic respiration (between rows in the case of sugar beet and before significant plant growth in the case of winter wheat) the spatial variability of median grain size and bulk density had the most consistent effect on the spatial variability of soil respiration. In contrast, soil moisture was less important and topsoil SOC had more or less no effect on $\mathrm{CO}_{2}$ effluxes. Only in two measuring phases (Phase 22008 and Phase 1 2009) did the combined analysis show that total erosion was one of the dominant variables for the spatial variability in $\mathrm{CO}_{2}$ effluxes. In general, the relatively inconsistent effect of soil erosion status on spatial variability of $\mathrm{CO}_{2}$ effluxes is somewhat surprising, as there are a number of different reasons which support the assumption that $\mathrm{CO}_{2}$ effluxes at erosional sites should be smaller than at depositional sites. A major reason for the observed behaviour might be the compensating effect of tillage and water erosion and the counteracting effects of both processes on soil respiration. This underlines the importance of field-scale studies to gain further insight into the interrelation of soil redistribution and $\mathrm{CO}_{2}$ effluxes.
\end{abstract}

\section{Introduction}

In terrestrial ecosystems soil respiration is the key pathway of $C$ to the atmosphere (Trumbore, 2006). As soils contain roughly twice the amount of $C$ than is stored in the atmosphere (Schlesinger, 2005), a small change in soil respiration rates can cause a significant alteration in atmospheric $\mathrm{CO}_{2}$ levels. Soil respiration is highly variable in time and space (e.g. Borken et al., 2002; Davidson et al., 2006; Fang et al.,

* Corresponding author at: Geographisches Institut, Universität zu Köln, Albertus Magnus Platz, 50923 Köln, Germany. Tel.: + 49221470 7802; fax: +49221 4705124. E-mail address: peter.fiener@uni-koeln.de (P. Fiener).
1998). The temporal variability at a single location can be determined relatively easily with a series of automated measurements over a certain time period (e.g. Liu et al., 2010), with different kinds of openor closed-chamber systems. In contrast, capturing spatial patterns of soil respiration, e.g. within a single arable field, is much more difficult, because small-scale variability requires a large number of spatially distributed measurements (Herbst et al., 2008; Rodeghiero and Cescatti, 2008). Hence, this small-scale spatial variability of soil respiration is often ignored in $\mathrm{C}$ balances on the field scale, but the integrative signal of $\mathrm{CO}_{2}$ efflux is determined by eddy-covariance methods (e.g. Reth et al., 2005a). Corresponding single-point soil respiration measurements are then used to distinguish between 
heterotrophic and autotrophic respiration as well as to fill gaps (especially at night) in the eddy-covariance measurements. However, there are also a number of studies dealing with temporal and spatial variability of soil respiration and its controls using automated or campaign measurements at spatially distributed locations (e.g. Epron et al., 2006; Herbst et al., 2009; Martin and Bolstad, 2009; Moyano, 2008; Pacific et al., 2008). Most of these studies focus on the variability of soil temperature as first-order control and soil moisture as secondorder control of soil respiration. Considering spatial variability, soil temperature can be important on larger spatial scales or on steep terrain, where soil temperature is variable due to differences in incoming radiation (e.g. Kang et al., 2000; 2003). However, at the field scale in the relatively flat terrain typical for agricultural areas, soil moisture is commonly more variable in space than to soil temperature. Therefore soil moisture is identified in many studies as the most important driver of spatial variability of respiration (e.g. Herbst et al., 2009).

Several studies also analyse the spatial variability of soil respiration in relation to patterns of different soil properties, like e.g. root biomass (Fang et al., 1998; Han et al., 2007; Reth et al., 2005b; Xu and Qi, 2001), quantity and quality of soil organic matter (Saiz et al., 2006; Schwendenmann et al., 2003; Scott-Denton et al., 2003; Soe and Buchmann, 2005), soil total porosity (Fang et al., 1998), pH value (Reth et al., 2005b), and microbial biomass (Xu and Qi, 2001). However, these studies were mostly carried out in woodlands or on flat terrain. On sloped land, some rare studies also investigated topographic position (Epron et al., 2006; Hanson et al., 1993; Parkin et al., 2005) as an influencing factor of soil respiration. To our knowledge, there are very few studies focusing on the relation between in situ measured spatial patterns of soil respiration and soil redistribution in arable landscapes. Van Hemelryck et al. (2010b) measured soil respiration shortly after an important erosion event on depositional and comparable sites without sedimentation on an arable field in the Belgian Loess Belt. The authors found a slightly increased mineralization of soil organic carbon (SOC) at depositional sites. But this effect was only important in the short term, as it vanished when the transported labile SOC fraction was completely mineralized. The results correspond to the findings of a laboratory study (Van Hemelryck et al., 2010a), where a similar but more pronounced increase in soil respiration after soil deposition was observed. In contrast to these results, Bajracharya et al. (2000) did not find any significant differences of $\mathrm{CO}_{2}$ effluxes at different slope positions with different erosional stages (slightly to severely eroded, and deposition) during a two-year field measurement campaign under continuous corn cultivation in the US. Similar results were obtained by Parkin et al. (2005) relating in situ measured soil respiration to landscape positions (summit, hillslope, and depressions) in three soybean (Glycine max. L.) and maize (Zea mays L.) fields. The authors did not measure any significant differences between $\mathrm{CO}_{2}$ effluxes at the different landscape positions and concluded that this was probably a result of a root respiration dominated system under fully grown crops.

Despite these inconsistent results, soil redistribution was found to have large effects on the spatial variability of a number of soil properties which potentially affect the spatial variability of soil respiration, e.g. SOC content (e.g. Berhe et al., 2007; Dlugoß et al., 2010; Harden et al., 1999; Mabit et al., 2008; Quine and Van Oost, 2007; Van Oost et al., 2007), nutrient content (Berhe et al., 2007), and soil texture (Heckrath et al., 2005; Papiernik et al., 2007). Hence, there is a general need for further investigation of in situ measured soil respiration as affected by soil redistribution.

Against this background, the main objectives of this study are (i) to evaluate the effects of erosion and deposition on in situ measured heterotrophic as well as combined heterotrophic and autotrophic soil respiration in a small agricultural watershed, and (ii) to determine further parameters (soil and plant properties) affecting the spatial variability of soil respiration and potentially modifying spatial patterns of SOC stocks.

\section{Materials and methods}

\subsection{Test site}

The test site is located about $30 \mathrm{~km}$ southeast of Cologne in North Rhine-Westphalia, Germany. It is part of a small watershed of approximately 4.2 ha (125 to $154 \mathrm{~m}$ above sea level, $50^{\circ} 43^{\prime} \mathrm{N}, 7^{\circ} 12^{\prime}$ E; Fig. 1). Slopes range from $1^{\circ}$ in the western part up to $9^{\circ}$ in the eastern part, with a flat-bottomed thalweg area heading to the outlet.

The mean annual air temperature is $10.0^{\circ} \mathrm{C}$ and the average annual precipitation is $765 \mathrm{~mm}(1990-2006)$. Rainfall is more or less equally distributed throughout the year, with the highest rainfall intensities due to convective storms between May and October (data from the German Weather Service station at Bonn-Roleber, about $1 \mathrm{~km}$ to the west at $159 \mathrm{~m}$ above sea level).

Based on a loess-cover, silty and silt-loamy soils classified as Alfisols (Soil Survey Staff, 1999) have developed. The watershed is intensively used in a crop rotation of sugar beet (Beta vulgaris L.), winter wheat (Triticum aestivum L.), and winter barley (Hordeum vulgare L.). Since 1980 a soil conservation system has been established, with reduced soil disturbance and with mustard (Sinapis arvensis L.) cultivated as a cover crop after winter barley.

\subsection{Soil respiration, soil temperature, and soil moisture}

Soil respiration, soil moisture, and soil temperature were measured during three crop cycles in 2007, 2008, and 2009. During the first measuring period sugar beet was cultivated, followed by two years of winter wheat (as an exception to the overall crop rotation). Bi-weekly to weekly measurements were carried out between 23 May and 18 August 2007, between 8 January and 28 July 2008, and between 25 February and 13 July 2009. In each crop cycle measurements were carried out at 20-22 locations in the eastern part of the watershed (Fig. 1), to cover different erosional and depositional sites as well as reference sites (at the upslope catchment boundaries).

An automated closed dynamic chamber designed for survey measurements (LICOR 8100-103, Lincoln, USA) was used in combination with an infrared gas analyser ( $\mathrm{LI}-8100$ ) to measure soil respiration. The chamber was closed for $120 \mathrm{~s}$ and the linear increase of $\mathrm{CO}_{2}$ concentration in the chamber was used to estimate soil respiration. Measurements were carried out on polyvinyl chloride collars ( $\varnothing$ $20 \mathrm{~cm}$ ) inserted $1-2 \mathrm{~cm}$ into the soil one week before the first measurement. The offset of the soil collars necessary for the calculation of the $\mathrm{CO}_{2}$ efflux in the chamber was determined at each measuring date. In 2007, under sugar beet, the collars were placed between the plant rows, while for winter wheat the seedlings were carefully handpicked inside the collars one week before the first measurement. The location of the collars was determined using a dGPS with a horizontal accuracy of 0.5 to $1.0 \mathrm{~m}$. Since the locations of crop rows as well as of wheelings differed slightly between the different years, soil collars could not be placed in exactly the same positions in the three measurement periods. At each measuring point soil respiration was determined one to four times a day. Measurement campaigns always started at approximately 10 a.m. and ended between $11.30 \mathrm{a} . \mathrm{m}$. and 4 p.m. depending on the number of measurements per collar.

A thermocouple soil temperature probe was connected to the Licor LI-8100 system, and soil temperature was simultaneously measured at a depth of $3 \mathrm{~cm}$ for each measurement. Topsoil moisture $(<6 \mathrm{~cm})$ was measured by frequency domain reflectrometry (FDR) (Theta Probe ML2×, Delta-T Devices, UK). Five measurements around each soil collar were taken on each measuring day, and the arithmetic mean of these five measurements was taken as the corresponding soil moisture. 


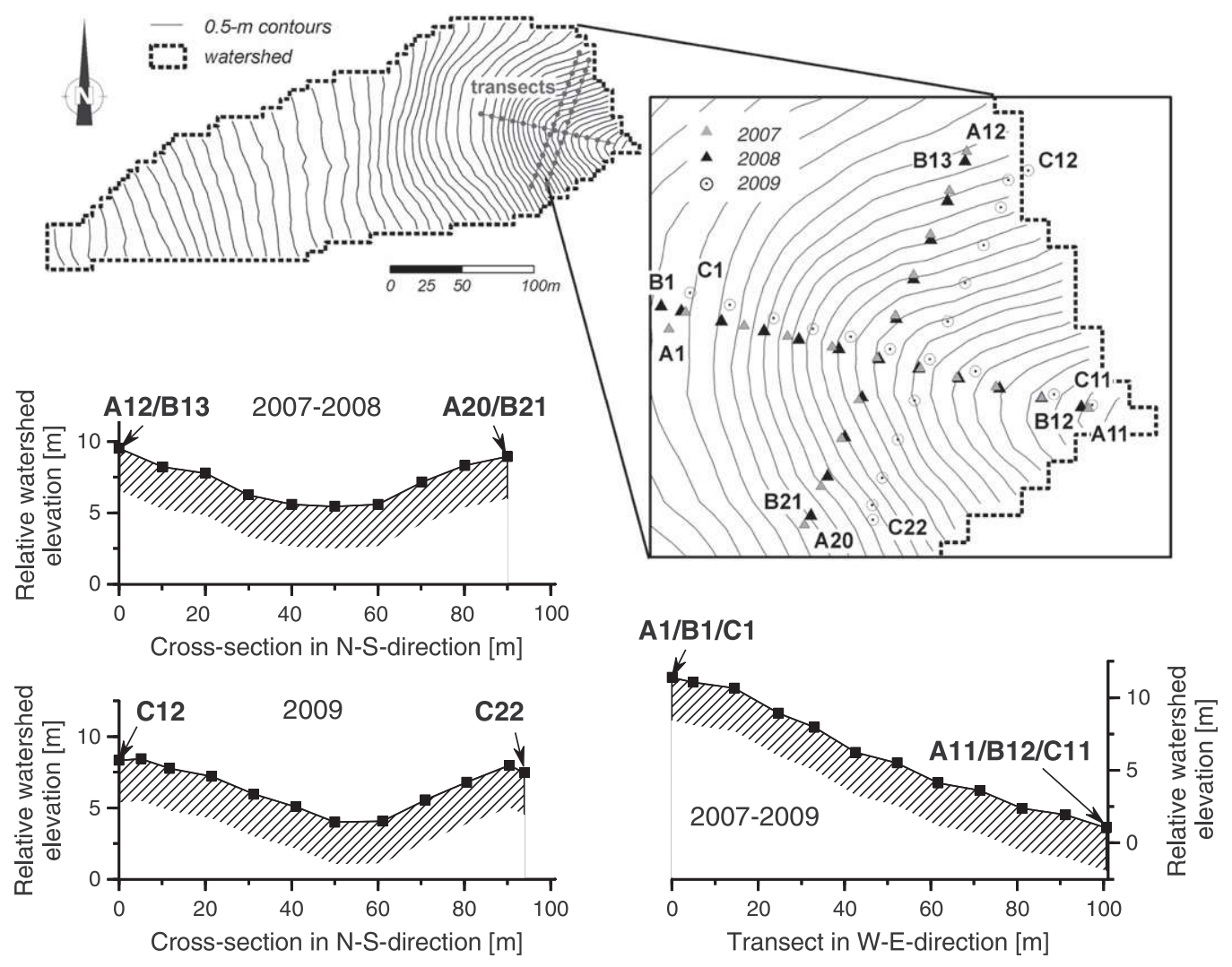

Fig. 1. Location of the measuring collars along cross-sections and transects within the test site; measurement locations in 2007, 2008, and 2009 are indicated by A, B, and C, respectively; note that the $\mathrm{Y}$-axis is four-times inflated.

\subsection{Soil and vegetation sampling and analysis}

At the end of each measurement period soil samples were taken inside of each soil collar. Two cores were extracted with a $5 \mathrm{~cm}$ diameter soil auger (Eijkelkamp, NL) to a depth of $0.25 \mathrm{~m}$. One core was used to determine soil bulk density by weighing the soil samples after oven drying at $105{ }^{\circ} \mathrm{C}$ (volumetric core method). The other was used to determine SOC and $\mathrm{N}$ contents, $\mathrm{pH}$ value, and soil texture. Roots, as well as recognisable undecomposed plant residues, were hand-picked. Soil samples were then dried at $105^{\circ} \mathrm{C}$ for $24 \mathrm{~h}$, ground, and coarse particles were separated by $2 \mathrm{~mm}$ sieving. Although the loess soils in the area are in most cases deeply decalcified, all soil samples were checked for lime $\left(\mathrm{CaCO}_{3}\right)$ with hydrochloric acid (10\%). If any inorganic $\mathrm{C}$ content was recognised, it was destroyed by means of hydrochloric acid. SOC and $\mathrm{N}$ contents were then determined by dry combustion using a CNS elemental analyser (vario EL, Elementar, Germany). Soil texture was determined by the combined sieve-pipette method (Deutsches Institut für Normung, 2002). The median grain size diameter $D_{50}$ was calculated following Shirazi et al. (1988). The $\mathrm{pH}$ value was determined in a $0.01 \mathrm{M} \mathrm{CaCl}_{2}$ solution (Deutsches Institut für Normung, 2006). Besides the topsoil parameters measured in the collars, geostatistically interpolated SOC data of two subsoil layers $(0.25-0.50 \mathrm{~m}$ and $0.50-$ $0.90 \mathrm{~m}$ ), derived from a measuring grid of 17.7 by $17.7 \mathrm{~m}$, were taken from an earlier study (Dlugoß et al., 2010).

To estimate differences in the potential carbon inputs by plants, plant heights were measured in concordance with the respiration measurements near each soil collar. Mean plant height as proxy variable for biomass was used to prevent destructive biomass measurements during the growing period as well as to gain some information concerning the possibility of roots growing under the collars. Moreover, total dry biomass before harvest was determined. Therefore, in 2007 three sugar beet plants were sampled, and in 2009 half a square metre of winter wheat was harvested close to each soil collar. The plants were dried at $70{ }^{\circ} \mathrm{C}$ and then weighed.

\subsection{Soil redistribution modelling}

Soil redistribution patterns were determined applying the longterm soil erosion and sediment delivery model WaTEM/SEDEM (Van Oost et al., 2000; Van Rompaey et al., 2001; Verstraeten et al., 2002), as integrated in the SPEROS-C Model (Dlugoß, 2011). The model consists of a water and tillage erosion component that can be run separately. The water erosion component uses an adapted version of the Revised Universal Soil Loss Equation (RUSLE; Renard et al., 1996). Tillage erosion is calculated with a diffusion-type equation adopted from Govers et al. (1994). The sediment transport pattern is calculated using the flux decomposition approach by Desmet and Govers (1996). The sediment is routed along this flow pattern towards the watershed outlet, taking into account its possible deposition. Deposition is controlled by the transport capacity calculated for each grid cell. The transport capacity is the maximal amount of sediment that can pass through a grid cell and is assumed to be proportional to the potential rill (and ephemeral gully) erosion volume (Van Rompaey et al., 2001). The model was applied in a 6.25 by $6.25 \mathrm{~m}$ grid. The erosion component of SPEROS-C was satisfactorily validated against (i) erosion-induced spatial patterns in SOC depth distributions and (ii) two depth profiles of ${ }^{14} \mathrm{C}$ AMS (accelerator mass spectrometry) at depositional sites. For details of model implementation and validation see Dlugoß (2011).

\subsection{Data analysis}

A general difficulty in analysing the spatial variance of $\mathrm{CO}_{2}$ effluxes based on survey measurements is the potential temporal trend in soil 
temperature and hence soil respiration during a measurement day. In our case it took about $1.5 \mathrm{~h}$ to survey the 20-22 locations (Fig. 1). During each measuring day one to four surveys were carried out and measurements always started at approximately 10 a.m. During almost all surveys ending before 2 p.m. an increase in soil temperature was observed, while for longer measuring days soil temperature tended to decrease again later on. As a random measuring order of the different collars was not possible, the potential trends in soil temperature during a measuring day may introduce a systematic spatial pattern of measured $\mathrm{CO}_{2}$ effluxes. To define variables that explain the spatial patterns of soil temperature and soil respiration, this potential trend must be carefully evaluated and removed. Compared to soil respiration, soil temperature is more closely linked to the time of day. Therefore, we first carried out a detrending of soil temperature data (using soil temperature vs. time of measurement) and analysed potential spatial relations between soil temperature and erosion/deposition status. Second, we standardised the $\mathrm{CO}_{2}$ efflux measurements to a temperature of $15^{\circ} \mathrm{C}$ for the analysis of further explanatory variables.

The relation between soil temperature and time of measurement was in most cases well described by first- (measurements before approximately 2 p.m.) or second-order (measurement till late afternoon) polynomial regressions. If these regressions were significant ( $\mathrm{p}<0.05$; true for $89 \%$ of all measuring days), this relation between soil temperature and measuring time was used for detrending. This resulted in a synchronisation of soil temperature at all measuring locations to 12 noon. If no significant trend in soil temperatures was detected, the mean soil temperature of all measurements at a soil collar was used for further analysis. The mean detrended soil temperatures at each collar and each measuring phase were used to determine the potential spatial differences in soil temperature at different landscape positions, which may result from differences in incoming radiation or soil moisture and hence evaporation differences. In the measuring phases where a significant relation between soil temperature and erosion/deposition status was determined, the maximum erosion-induced difference in $\mathrm{CO}_{2}$ efflux resulting from temperature differences was estimated. Therefore, an exponential equation (Eq. (1)) was fitted to the measured $\mathrm{CO}_{2}$ efflux and soil temperature data.

$\mathrm{CO}_{2}-$ efflux $=\beta_{0} e^{\beta_{1} T}$

where $\beta_{0}$ and $\beta_{1}$ are fit-parameters and $T$ is the soil temperature [ ${ }^{\circ} \mathrm{C}$ ]

Based on the fit-parameters determined for each collar, the change in flux in the case of higher or lower temperatures at erosional and depositional sites can be calculated for a given base temperature, which was set to $15^{\circ} \mathrm{C}$ as an average soil temperature over all measuring periods.

After evaluating the effects of erosional status on soil temperature, additional explanatory variables for spatial differences in soil respiration were analysed based on $\mathrm{CO}_{2}$ effluxes standardised to a temperature of $15^{\circ} \mathrm{C}$. The slope of the linear regression between all soil respiration and soil temperature measurements made in each year (Fig. 2) was used for this standardisation (subsequently the standardised measurements are referred as $\mathrm{sCO}_{2}$-efflux). On the one hand, this relatively simple procedure eliminates the temperature effect arising from the experimental set-up. On the other hand, the use of one regression for all collars within a year prevents introducing any bias in the relative differences between measurements in the case of equal temperature. Moreover, the standardisation to one temperature allows calculating mean $\mathrm{CO}_{2}$ effluxes at each location without dominating these means by high $\mathrm{CO}_{2}$ effluxes during warm days, and also allows for a comparison between different measuring phases.

In the two winter wheat years (2008 and 2009), mean standardised $\mathrm{CO}_{2}$ effluxes per collar were calculated for phases clearly dominated by heterotrophic respiration (Phase 1 ) and phases when autotrophic respiration was becoming increasingly important due to

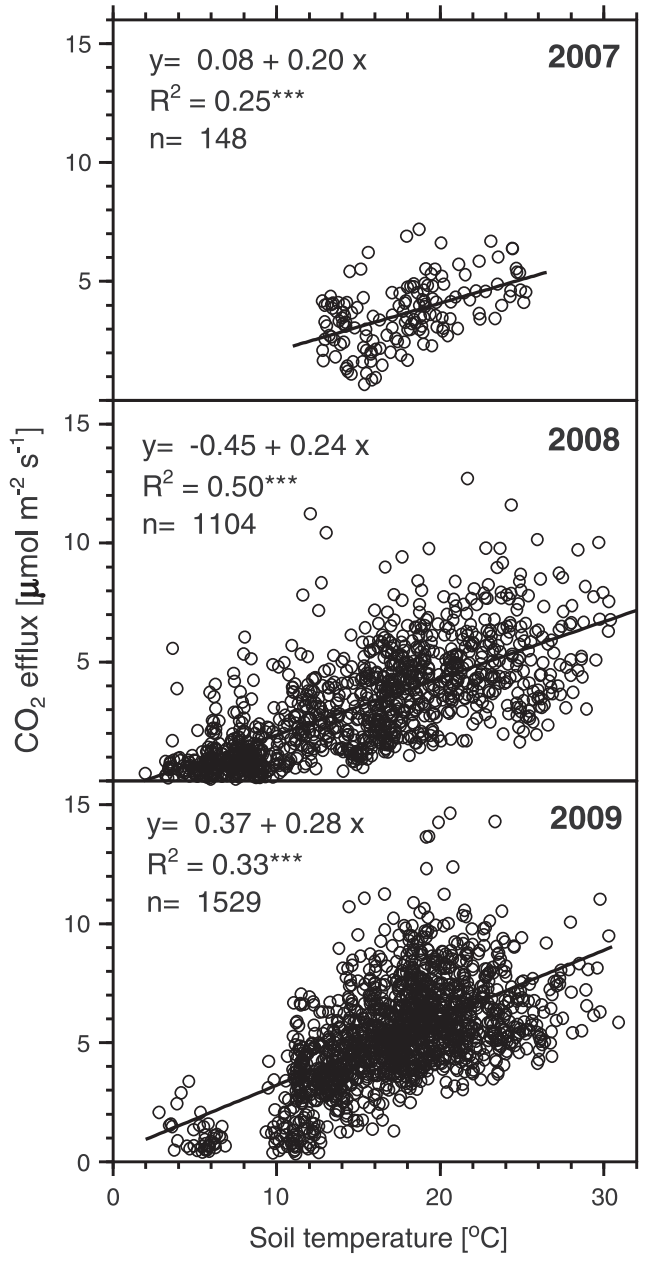

Fig. 2. Measured $\mathrm{CO}_{2}$ effluxes vs. measured soil temperatures under sugar beet (2007) and winter wheat (2008 and 2009); regression equations of each year were used for the $\mathrm{CO}_{2}$ efflux standardisation.

root growth under the collars (Phase 2, from mid-April onwards [wheat plants $>0.1 \mathrm{~m}]$ ). However, in the case of sugar beet (2007) when the collars were located between the plant rows, the effect of roots should be small and therefore one mean $\mathrm{sCO}_{2}$-efflux was calculated for the whole measuring period.

To determine explanatory variables (soil and crop properties, erosion status) of the spatial variability of $\mathrm{sCO}_{2}$-effluxes, linear regression between these variables and the $\mathrm{sCO}_{2}$-effluxes were performed. Prior to this, all variables were tested for normality using Q-Q-plots and applying the Shapiro-Wilk test (Shapiro and Wilk, 1965). Variables not normally distributed were log-transformed. Significance levels of the regressions were calculated using two-sided Student's t-tests. However, a linear regression based analysis of explanatory variables is difficult to interpret if these variables are intercorrelated. To tackle this problem and to determine the most important structure in the combined explanatory variables, a principal component analysis was performed and the major drivers of each significant principal component (PC) were determined. Based on this pre-analysis, the significant PCs of all explanatory variables were correlated to $\mathrm{SCO}_{2}$-effluxes.

The principal components of the explanatory variables were computed using Matlab 2009b (MathWorks Inc., Natick, Massachusetts, 2009) with the built-in singular value decomposition function (SVD). Before computation all variables were standardised to have a zero mean and a standard deviation of one. The confidence limits for the significance of the PCs were estimated with a Monte Carlo analysis 


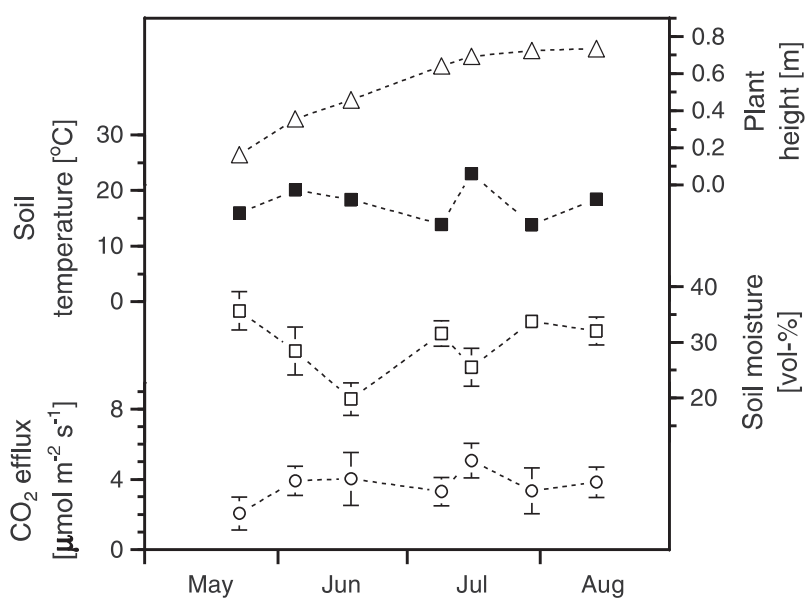

Fig. 3. Temporal variability of mean plant height (open triangles), topsoil temperature (filled rectangles), and moisture (open rectangles) as well as mean $\mathrm{CO}_{2}$ efflux (open circles) at the 20 measuring locations in 2007; error bars ( \pm standard deviation) indicate the spatial variability of measurements during individual campaigns.

of one thousand realisations of normally distributed surrogate data sets in the dimension of the original data set (for details see Korres et al., 2010). All further statistical analyses were carried out using the GNU R version 2.6 (R Development Core Team, 2007).

\section{Results}

\subsection{Soil respiration, soil temperature, and soil moisture}

During the three-year study, soil respiration, moisture, and temperature were determined on 42 days resulting in a total of 2781 measurements. In general, soil respiration showed a typical seasonality with relatively low effluxes at the beginning of the growing periods, which increased with increasing soil temperature and plant growth (Figs. 3-5). For the winter wheat, this seasonality was more pronounced due to the prolonged measuring campaign (Jan/Feb to July), with more distinct differences in soil temperature and an increasing proportion of autotrophic respiration throughout the measuring period. The more important root respiration for winter wheat compared to sugar beet (where the collars were placed between

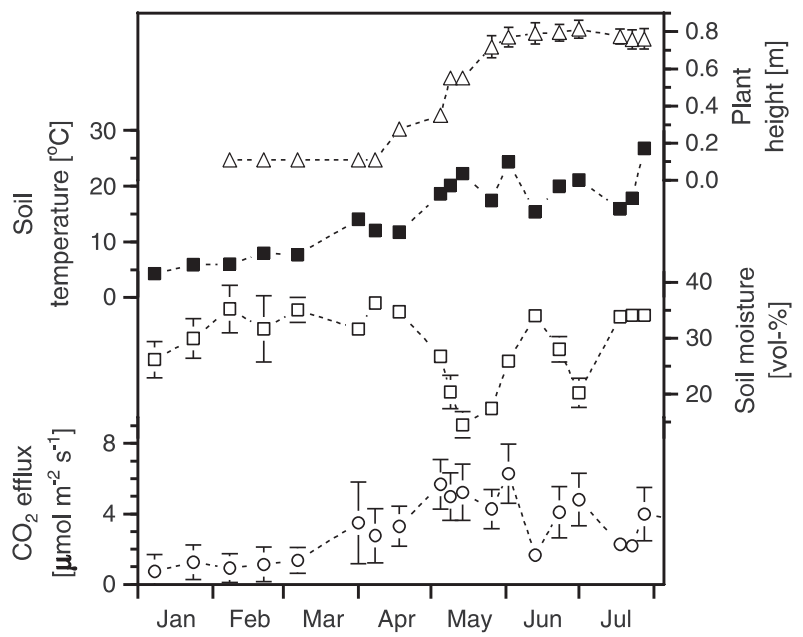

Fig. 4. Temporal variability of mean plant height (open triangles), topsoil temperature (filled rectangles), and moisture (open rectangles) as well as mean $\mathrm{CO}_{2}$ efflux (open circles) at the 20 measuring locations in 2008; error bars ( \pm standard deviation) indicate the spatial variability of measurements during individual campaigns; variability in plant height could only be determined from end of May to harvest.

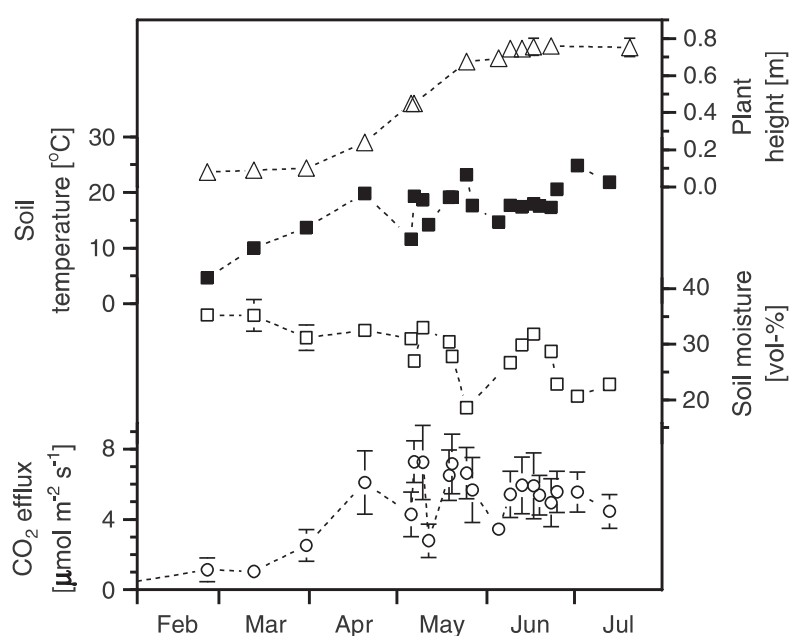

Fig. 5. Temporal variability of mean plant height (open triangles), topsoil temperature (filled rectangles), and moisture (open rectangles) as well as mean $\mathrm{CO}_{2}$ efflux at the 22 measuring locations in 2009; error bars ( \pm standard deviation) indicate the spatial variability of measurements during individual campaigns; variability in plant height could only be determined from beginning of June to harvest.

plant rows) is also indicated by (i) the smaller $\mathrm{CO}_{2}$ effluxes under fully grown sugar beet compared to wheat, and (ii) a slight decline in measured $\mathrm{CO}_{2}$ effluxes at the end of the growing period due to wheat senescence (Figs. 4-5).

Comparing temporal variability of $\mathrm{CO}_{2}$ effluxes with temporal variability of soil moisture at the collars (Figs. 3-5), there was no obvious relation during sugar beet cultivation, when mean soil moisture was in a mid-range on all measuring days (between 19.3 and 35.0 vol.\%). Under winter wheat, especially in May, some dry days seem to limit soil respiration (minimal mean soil moisture in May is 14.6 and 18.8 vol.\% in 2008 and 2009, respectively).

\subsection{Soil redistribution}

According to the modelled total erosion rates (comprising soil redistribution by water and by tillage operations; Table 1 ), seven of the measuring collars were located at erosional sites and 13 at depositional sites in 2007 and 2008. Due to the shift of the location of the northsouth cross-section of collars (Fig. 1) in 2009, 12 collars were modelled as erosional sites while 10 represented depositional sites in 2009 (Table 1). Total erosion and deposition at the 2007, 2008, and 2009 collars range between a soil loss of $-0.95,-0.93$, and $-0.97 \mathrm{~mm} \mathrm{a}^{-1}$ and a soil gain of $1.84,1.90$, and $1.70 \mathrm{~mm} \mathrm{a}^{-1}$, respectively. In the following, erosion is always given in negative values and deposition in positive values. Concerning the overall soil redistribution within the

Table 1

Arithmetic mean and standard deviation (SD) of modelled total, tillage, and water erosion at the erosional and depositional sites in 2007,2008, and 2009; note that areas of erosion and deposition are defined referring to total erosion.

\begin{tabular}{|c|c|c|c|c|c|c|c|}
\hline & \multirow[t]{3}{*}{$\mathrm{n}$} & \multicolumn{2}{|c|}{ Total erosion } & \multicolumn{2}{|c|}{ Water erosion } & \multicolumn{2}{|c|}{ Tillage erosion } \\
\hline & & Mean & SD & Mean & SD & Mean & SD \\
\hline & & \multicolumn{6}{|c|}{$\mathrm{mm} \mathrm{a}^{-1}$} \\
\hline \multicolumn{8}{|l|}{2007} \\
\hline Erosion & 7 & -0.95 & 0.73 & -0.77 & 1.62 & -1.24 & 0.95 \\
\hline Deposition & 13 & 1.84 & 1.05 & 2.71 & 1.95 & -2.30 & 1.21 \\
\hline \multicolumn{8}{|l|}{$2008^{*}$} \\
\hline Erosion & 7 & -0.93 & 0.65 & -0.69 & 1.68 & -1.28 & 0.91 \\
\hline Deposition & 13 & 1.90 & 0.99 & 2.70 & 2.16 & -2.19 & 1.16 \\
\hline \multicolumn{8}{|l|}{2009} \\
\hline Erosion & 12 & -0.97 & 0.70 & -0.72 & 0.60 & -0.25 & 0.22 \\
\hline Deposition & 10 & 1.70 & 0.94 & 2.63 & 1.35 & -0.93 & 0.51 \\
\hline
\end{tabular}


Table 2

Correlation of individual and mean topsoil temperatures $T_{S}$ (at a depth of $0.03 \mathrm{~m}$ ) with total erosion $E_{\text {tot }}$ at the measuring locations; for the winter wheat years a Phase 1 , indicating exclusively heterotrophic respiration, and a Phase 2, comprising heterotrophic and autotrophic respiration, were treated separately; mean soil temperature of erosional sites $T_{s \_ \text {erosion }}$ was compared with mean soil temperature at depositional sites $T_{s_{-} \text {deposition; }}$ asterisks give significant levels $\left({ }^{* * *}\right.$ is $\mathrm{p}<0.001$; ${ }^{* *}$ is $\mathrm{p}<0.01$, and ${ }^{*}$ is $\mathrm{p}<0.05$ ).

\begin{tabular}{|c|c|c|c|c|c|c|}
\hline \multicolumn{5}{|c|}{ Individual $T_{s}$ measurements vs. $E_{\text {tot }}$} & \multicolumn{2}{|c|}{ Mean $T_{s}$ vs. $E_{\text {tot }}$} \\
\hline Measuring year/phase & $\begin{array}{l}\text { No. of measurement } \\
\text { dates }\end{array}$ & $\begin{array}{l}\text { No. of significant } \\
\text { correlations }\end{array}$ & Significant Pearson R's & $\begin{array}{l}\text { Mean } T_{s_{\text {_erosion }}-}- \\
\text { Mean } T_{s_{-} \text {deposition }}\left[{ }^{\circ} \mathrm{C}\right]\end{array}$ & Pearson $\mathrm{R}$ & $\begin{array}{l}\text { Mean } T_{s_{-} \text {erosion }}- \\
\text { Mean } T_{s_{-} \text {deposition }}\left[{ }^{\circ} \mathrm{C}\right]\end{array}$ \\
\hline 2007 & 7 & 1 & $0.52^{*}$ & -1.0 & $0.61^{* *}$ & 0.0 \\
\hline Phase 12008 & 5 & 1 & $-0.56^{*}$ & 0.1 & -0.23 & 0.3 \\
\hline Phase 22008 & 14 & 0 & - & - & 0.22 & -0.1 \\
\hline Phase 12009 & 3 & 0 & - & - & -0.06 & 0.1 \\
\hline Phase 22009 & 14 & 4 & $\begin{array}{l}0.45^{*}, 0.66^{*} \\
0.52^{*}, 0.53^{*}\end{array}$ & $\begin{array}{l}-0.82,-0.18 \\
-0.44-0.37\end{array}$ & 0.21 & -0.3 \\
\hline
\end{tabular}

small watershed, the measuring locations represent the most dynamic area. In general, tillage erosion is the dominant redistribution process.

\subsection{Soil temperature and soil redistribution}

Due to the measuring set-up, it was not possible to directly determine the effect of spatial variable soil temperature on the spatial variability of $\mathrm{CO}_{2}$ effluxes. Therefore, the potential difference in $\mathrm{CO}_{2}$ efflux at erosional and depositional sites due to differences in soil temperature was analysed based on standardised soil temperatures (standardised to 12 noon on each measuring day). In the sugar beet year a significant correlation between mean standardised soil temperature at each collar and total erosion could be found, while no significant correlation was calculated for the winter wheat years (Table 2). In all years the difference in mean soil temperature between erosional and depositional sites was small (maximum $\pm 0.3{ }^{\circ} \mathrm{C}$ ), while there was a distinct difference in mean erosion/deposition rate (Table 1). Focusing on individual measuring dates, under sugar beet there was only one significant positive correlation between standardised soil temperature and total erosion, governing the overall correlation of all seven measuring dates. For this individual measuring day the mean standardised soil temperature difference between erosional and depositional sites was $1.0^{\circ} \mathrm{C}$ (Table 2). Under winter wheat it was only in the Phase 2009 that some measuring days showed a significant positive correlation between soil temperature and total erosion. In general, the positive correlations (except for Phase 1 2008) are somewhat surprising as it could be expected that soils at depositional sites are wetter and therefore cooler due to higher evaporation rates. The higher soil temperatures at the depositional sites might result from their location on a flat, southeast-facing slope collecting slightly more incoming radiation, which was especially important in the case of sugar beet when measurements were mostly carried out between approximately 10 a.m. and 12 noon.

In general, the standardised soil temperatures only significantly correlated in a few cases with total erosion. In these cases the soil temperature difference was always below $1.0^{\circ} \mathrm{C}$ (Table 2). Hence, the prevenient erosion-induced difference in $\mathrm{CO}_{2}$ efflux resulting from differences in soil temperature at erosional and depositional sites was small and not consistent. Therefore no further estimates of $\mathrm{CO}_{2}$ efflux effects according to Eq. (1) were necessary. For the further analysis of spatial variability of $\mathrm{CO}_{2}$ effluxes, potential soil temperature effects during individual measuring days were removed by the $\mathrm{CO}_{2}$ efflux temperature standardisation procedure.

\subsection{Standardised soil respiration and soil redistribution}

Comparing relative differences in standardised $\mathrm{CO}_{2}$ effluxes $\left(\mathrm{sCO}_{2-}\right.$ efflux) and modelled soil erosion shows inconsistent relations (Fig. 6). During four of the five measuring phases the mean $\mathrm{sCO}_{2}$-effluxes at the depositional sites were slightly larger than the mean $\mathrm{sCO}_{2}$-effluxes at the erosional sites. However, mean values at erosion and deposition sites did not differ significantly (even using a significance level of $\mathrm{p}<0.1$ ). Under winter wheat in 2008 there was only a slightly larger difference in site-specific mean $\mathrm{sCO}_{2}$-effluxes for the phase of combined autotrophic and heterotrophic respiration (Phase 2), as

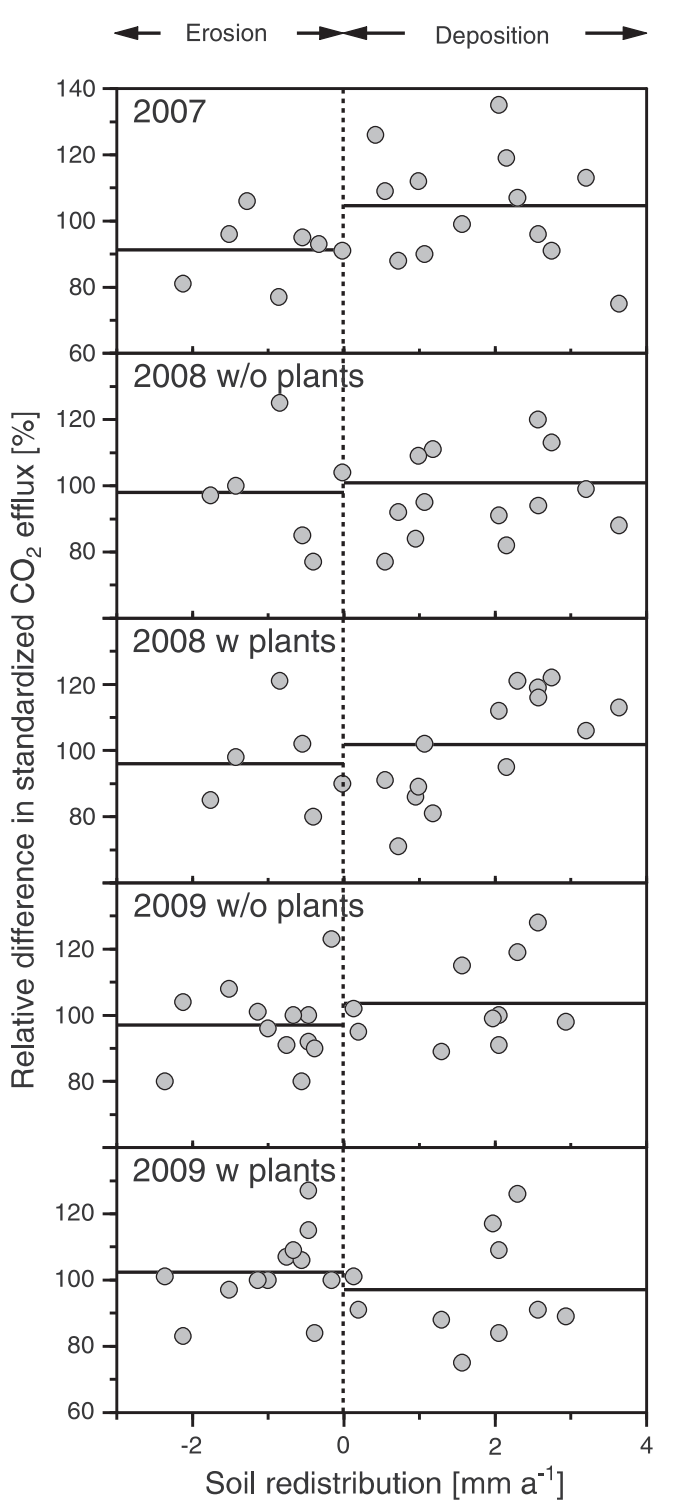

Fig. 6. Relative difference in $\mathrm{SCO}_{2}$-efflux summarised from all measurements carried out at each collar in each measuring phase vs. modelled soil redistribution rates at the different collars installed in 2007, 2008, and 2009; horizontal lines indicate mean relative difference in $\mathrm{sCO}_{2}$-efflux for erosional and depositional sites, respectively. 
compared to the exclusive heterotrophic respiration. This indicates that there was no systematic decrease in plant growth and hence root respiration at erosional sites compared to depositional sites. The missing spatial difference in plant activity and growth in 2008 was also indicated by the measured plant heights (as somewhat weak proxy for biomass production and hence root respiration), which did not differ significantly either in seasonal average $(0.42 \pm 0.0$ and $0.41 \pm 0.0 \mathrm{~m}$, for erosional and depositional sites, respectively) or in average maximum values $(0.76 \pm 0.0$ and $0.76 \pm 0.1 \mathrm{~m}$, respectively). In Phase 12009 (February-March) sCO tendency as observed in 2008, while the mean $\mathrm{sCO}_{2}$-efflux in Phase 2 was slightly larger at erosional sites compared to depositional sites. This probably results from a more dominant root respiration, especially in May, which seemed not to be related to patterns in soil redistribution at our test site. The independence of spatial variability of root respiration from soil redistribution patterns in 2009 was also indicated by the small differences (not significant) between the erosional and the depositional sites, referring to mean plant height $(0.68 \pm 0.0$ and $0.66 \pm 0.0 \mathrm{~m}$, resp.) as well as above-ground dry biomass determined before harvest $\left(1.58 \pm 0.30\right.$ and $\left.1.54 \pm 0.31 \mathrm{~kg} \mathrm{~m}^{-2}\right)$.

\subsection{Standardised soil respiration vs. soil/plant variables and soil redistribution}

As the spatial variability of $\mathrm{sCO}_{2}$-effluxes are only slightly affected by soil erosion patterns alone, correlation analyses were carried out between $\mathrm{sCO}_{2}$-effluxes and topsoil, subsoil, and crop properties (Table 3 ), erosion status and PCs calculated from all these explanatory variables. In 2007 only topsoil moisture $S M$ and bulk density $B D$ were significantly correlated $(\mathrm{p}<0.1)$ with mean $\mathrm{SCO}_{2}$-effluxes (Table 4 ). There seemed to be a tendency that water availability was limiting respiration and therefore dryer sites with smaller porosity showed smaller $\mathrm{sCO}_{2}$-effluxes and vice versa. Soil moisture explained $73 \%$ of variability in PC1 (Tables 4,5), which is also strongly correlated to SOC below $0.25 \mathrm{~m}$ and all erosion variables, while $B D$ explains $42 \%$ of the variability in PC3, also represented by $D_{50}$ and root biomass. However, none of the PCs correlated with sCO2-effluxes (Table 4). The missing correlation with PC1 indicates that soil erosion patterns, even if combined with other potential explanatory variables, had no important effect upon sCO2-effluxes in 2007.

In 2008 an inconsistent behaviour for the different measuring phases was observed. Until the beginning of April, without the influence of autotrophic respiration, mean $\mathrm{sCO}_{2}$-effluxes only correlated $(\mathrm{p}<0.01)$ with $D_{50}$ (Table 6). As $D_{50}$ and also $B D$ were the most important variables determining $\mathrm{PC}$, there was also a significant correlation $(\mathrm{p}<0.1)$ between $\mathrm{sCO}_{2}$-effluxes and PC3 (Table 6). Although SM was relatively high ( $>30$ vol.\% except for early January) in Phase 1 of 2008 , there was neither a correlation to measured $\mathrm{CO}_{2}$ fluxes nor to $D_{50}$ or PC3. Hence, the relevance of $D_{50}$ might lie in the limitation of diffusion in case of fine textures. In Phase 2 of the same year (April to July) a relative large number of explanatory variables, including all erosion variables, were significantly correlated with $\mathrm{sCO}_{2}$-effluxes (Table 7). As this indicates a multiple interaction between different variables, it seemed to be more promising to analyse significant PCs (Table 5) derived from these variables. Standardised $\mathrm{CO}_{2}$-effluxes significantly correlated with PC1 $(p<0.05)$ and PC2 $(p<0.1)$, representing $31 \%$ and $19 \%$ of flux variability, respectively. The strongest correlation between PC1 and any individual variable was found with erosion and subsoil SOC amounts, which were also strongly intercorrelated (Table 7). This indicates that the effect of soil redistribution on $\mathrm{sCO}_{2-}$ effluxes at least partly resulted from the erosion-induced changes of SOC depth distribution, while potential effects on plant and root growth were less pronounced at the test site. PC2, explaining a smaller amount of variability in $\mathrm{sCO}_{2}$-effluxes, was dominated by topsoil properties, but interestingly topsoil SOC amounts did not contribute to PC2 (Table 7).

Similar to Phase 1 2008, the most important variable in Phase 1 of 2009 that showed a highly significant correlation $(\mathrm{p}<0.001)$ with $\mathrm{sCO}_{2^{-}}$ effluxes was the median grain size $D_{50}$. Weaker correlations were found with other topsoil properties as well as with tillage $E_{t i l}$ and total erosion $E_{\text {tot }}$ (Table 8). In consequence $\mathrm{sCO}_{2}$-effluxes also correlated with both significant PCs (Tables 5, 8). While PC1 was dominated by topsoil properties, subsoil SOC and erosion variables, PC2 was dominated by bulk density and by further topsoil variables (Table 8). It is interesting to note that from univariate statistics $D_{50}$ was the most important variable, while for the combined analysis using $\mathrm{PCs}$ vs. $\mathrm{sCO}_{2}$-effluxes $\mathrm{BD}$ seemed to be more important (as also shown for Phase 1 2008). In Phase 2 of 2009 SM and pH were to some extent significantly correlated with $\mathrm{SCO}_{2}$-effluxes (Table 9). Compared to other explanatory variables, neither $S M$ nor $\mathrm{pH}$ dominated a single PC, hence none of the PCs significantly correlated with $\mathrm{sCO}_{2}$-effluxes. Moreover, it must be recognised that $\mathrm{pH}$ had only a minor effect on any of the significant PCs and might therefore be relatively unimportant for $\mathrm{sCO}_{2}$-effluxes with regards to multivariate analysis. Overall, the more or less missing

Table 3

Variables used for correlation analysis with standardised $\mathrm{CO}_{2}$ effluxes and with results of erosion modelling; $\mathrm{SD}$ is standard deviation and $\mathrm{CV}$ is coefficient of variation; for the winter wheat years mean topsoil moisture (Mean $S M$; depth $0-0.06 \mathrm{~m}$ ) was determined for a Phase 1, indicating exclusively heterotrophic respiration, and a Phase 2, comprising heterotrophic and autotrophic respiration, while for sugar beet only the mean over the total cropping period is given; topsoil properties were determined at the end of each measuring period within the respiration collars (depth: $0-0.25 \mathrm{~m}$ ); soil organic carbon $S O C$ amounts are also given for two subsoil layers $\left(\mathrm{SOC}_{50}\right.$ : $0.25-0.50 \mathrm{~m}$; $\mathrm{SOC}_{90}$ : $0.50-0.90 \mathrm{~m}$ ); $\mathrm{N}$ is soil nitrogen; $\mathrm{C} / \mathrm{N}$ is the ratio of $\mathrm{C}$ and $\mathrm{N}$, and $D_{50}$ gives the median grain size diameter.

\begin{tabular}{|c|c|c|c|c|c|c|c|c|c|c|c|}
\hline \multirow[b]{2}{*}{ Variable } & & \multirow[b]{2}{*}{ Unit } & \multicolumn{3}{|l|}{2007} & \multicolumn{3}{|l|}{2008} & \multicolumn{3}{|l|}{2009} \\
\hline & & & Mean & SD & $\mathrm{CV}(\%)$ & Mean & SD & $\mathrm{CV}(\%)$ & Mean & SD & $\mathrm{CV}(\%)$ \\
\hline \multirow{4}{*}{ Topsoil Mean SM } & Phase 1 & $\%$ & 29.03 & 1.96 & 6.76 & 31.7 & 2.52 & 7.94 & 33.8 & 2.30 & 6.81 \\
\hline & Phase 2 & $\%$ & & & & 28.1 & 1.24 & 4.40 & 27.4 & 1.09 & 3.96 \\
\hline & SOC & $\mathrm{g} \mathrm{m}^{-2}$ & 4161 & 501 & 12.0 & 4126 & 324 & 7.85 & 4204 & 787 & 18.7 \\
\hline & $\mathrm{N}$ & $\mathrm{g} \mathrm{m}^{-2}$ & 425 & 60.2 & 14.2 & 454 & 52.3 & 11.5 & 487 & 74.9 & 15.4 \\
\hline \multirow{4}{*}{ Topsoil properties } & $\mathrm{C} / \mathrm{N}$ & - & 9.97 & 1.57 & 15.7 & 9.29 & 1.47 & 15.8 & 8.60 & 0.41 & 4.83 \\
\hline & $\mathrm{pH}$ & - & 6.83 & 0.34 & 4.96 & 6.98 & 0.24 & 3.41 & 6.81 & 0.27 & 3.97 \\
\hline & $B D$ & $\mathrm{~g} \mathrm{~cm}^{3}$ & 1.44 & 0.05 & 3.39 & 1.30 & 0.04 & 3.16 & 1.38 & 0.10 & 6.93 \\
\hline & $D_{50}$ & $\mu \mathrm{m}$ & 11.2 & 1.75 & 15.6 & 11.0 & 2.11 & 19.1 & 10.9 & 1.64 & 15.0 \\
\hline \multirow{2}{*}{ Subsoil properties } & $\mathrm{SOC}_{50}$ & $\mathrm{~g} \mathrm{~m}^{-2}$ & 3100 & 887 & 28.6 & 3154 & 877 & 27.8 & 2967 & 858 & 28.9 \\
\hline & $\mathrm{SOC}_{90}$ & $\mathrm{~g} \mathrm{~m}^{-2}$ & 3213 & 1938 & 60.3 & 3271 & 1870 & 57.2 & 2929 & 1843 & 62.9 \\
\hline \multirow[t]{3}{*}{ Crop properties } & Biomass $^{a}$ & $\mathrm{~kg} \mathrm{~m}^{-2}$ & 2.80 & 0.92 & 32.5 & & & & 1.57 & 0.30 & 19.1 \\
\hline & Plant height ${ }^{\mathrm{b}}$ & $\mathrm{M}$ & & & & 0.42 & 0.02 & 4.31 & 0.67 & 0.03 & 4.18 \\
\hline & Root biomass ${ }^{c}$ & $\mathrm{~g} \mathrm{~m}^{-2}$ & 34.8 & 34.1 & 98.0 & 183 & 60.4 & 32.9 & 99.8 & 46.0 & 46.1 \\
\hline
\end{tabular}

\footnotetext{
a Above ground biomass at harvest around the collars.

b Mean plant height measured around the collars.
}

c After harvest within the collars. 


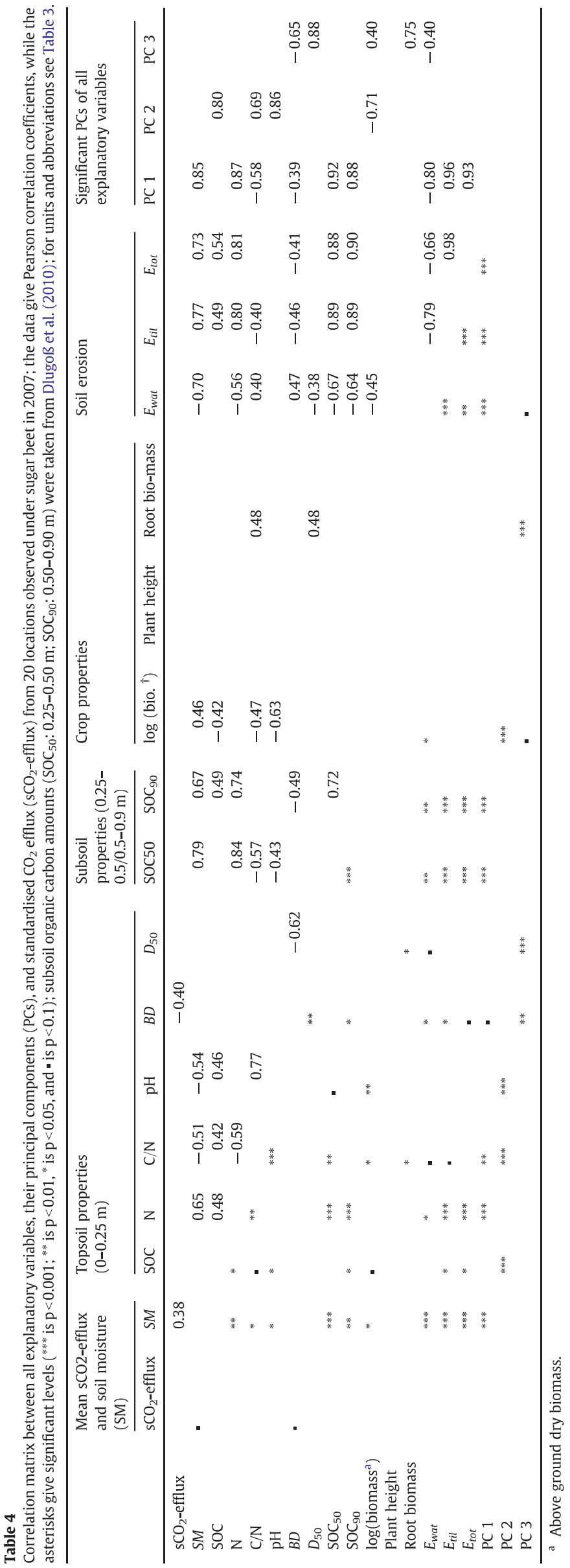

relation of spatial variability of $\mathrm{sCO}_{2}$-effluxes to any spatial pattern of the tested variables might result from a pronounced/increased importance of root respiration in 2009 as indicated by the highest measured $\mathrm{CO}_{2}$ effluxes in May 2009 (Figs. 3-5).

\section{Discussion}

When analysing $\mathrm{CO}_{2}$ effluxes at landscape positions with different erosion status, there are several reasons why one could expect reduced soil respiration at erosional sites and (slightly) increased soil respiration at depositional sites. These might directly or indirectly be caused by erosion processes or result from intercorrelations of erosion with other driving variables. Direct effects of erosion that possibly change $\mathrm{CO}_{2}$ effluxes are (i) the burial of SOC-rich soil below the plough layer at depositional sites, with a subsequent small contribution to respiration, and (ii) the decrease of SOC contents in the plough layer at erosional sites due to the intermixing of SOC-depleted subsoil material (Fig. 7). At our test site deposition of SOC is indicated by average deep profiles at depositional sites with relatively high subsoil SOC contents (Fig. 7). SOC depletion of the plough layer at erosional sites is, however, too small to show significant lower SOC amounts compared to the depositional sites (two-sided $t$ test). The small but insignificant decline in the plough layer SOC at erosional sites may have two reasons. On the one hand, differences in SOC amount between topsoil and subsoil are unincisive in the loess-burden soil at the test site. The modelled mean soil loss of $-0.9 \mathrm{~mm} \mathrm{a}^{-1}$ at all erosional sites would only lead to mean topsoil SOC loss of $6.0 \mathrm{~g} \mathrm{~m}^{-2} \mathrm{a}^{-1}$, if ploughinduced intermixing of subsoil was the only path of carbon loss. On the other hand, a long-term depletion of topsoil might partly be compensated for by processes of dynamic replacement (Stallard, 1998), as indicated by studies comparing SOC in soil profiles with ${ }^{137}$ Cs derived erosion rates (e.g. Quine and Van Oost, 2007).

A second direct effect of soil redistribution is the potentially selective transport and deposition of different soil carbon fractions, especially in case of interrill erosion (Kuhn et al., 2009). Interrill erosion potentially removes carbon-rich, near-surface topsoil (Starr et al., 2000), while transport and deposition processes can lead to an enrichment of fine and less dense material in surface runoff and a potential loss of carbon via mineralization during transport (Polyakov and Lal, 2004). The removal of carbon-rich, near-surface topsoil may lead to a decline in plough layer carbon amount and hence a reduction of $\mathrm{CO}_{2}$ effluxes at erosional sites. The effects at the depositional sites are less clear. On the one hand, deposited sediments should be depleted in carbon compared to erosional sites, as the most stable SOC is associated with fine particle-size classes and the most labile carbon is available in coarse but less dense particle-size classes (Amelung and Zech, 1999), both of which are preferentially lost with surface runoff. This should reduce $\mathrm{CO}_{2}$ effluxes at depositional sites. On the other hand, the breakdown of aggregates during transport or during drying processes at deposition sites may lead to a large amount of easily mineralizable carbon at the surface, which results in increasing $\mathrm{CO}_{2}$

Table 5

Explained variance of different principal components (PCs) derived from all explanatory variables given for each measuring phase in Tables 4, 6 to 9; only the PCs are given, which are different from random data; confidence limits were determined by Monte Carlo simulations on random data with equal variance and mean.

\begin{tabular}{llll}
\hline \multirow{2}{*}{$\begin{array}{l}\text { Measuring } \\
\text { year/phase }\end{array}$} & \multicolumn{4}{l}{ Explained variance [\%] } \\
\cline { 2 - 4 } & PC1 & PC2 & PC3 \\
\hline 2007 & 42.9 & 19.1 & 16.1 \\
Phased 1 2008 & 40.3 & 24.0 & 13.7 \\
Phased 2 2008 & 37.2 & 21.0 & 14.9 \\
Phased 1 2009 & 55.3 & 15.9 & \\
Phased 2 2009 & 43.3 & 16.6 & \\
\hline
\end{tabular}



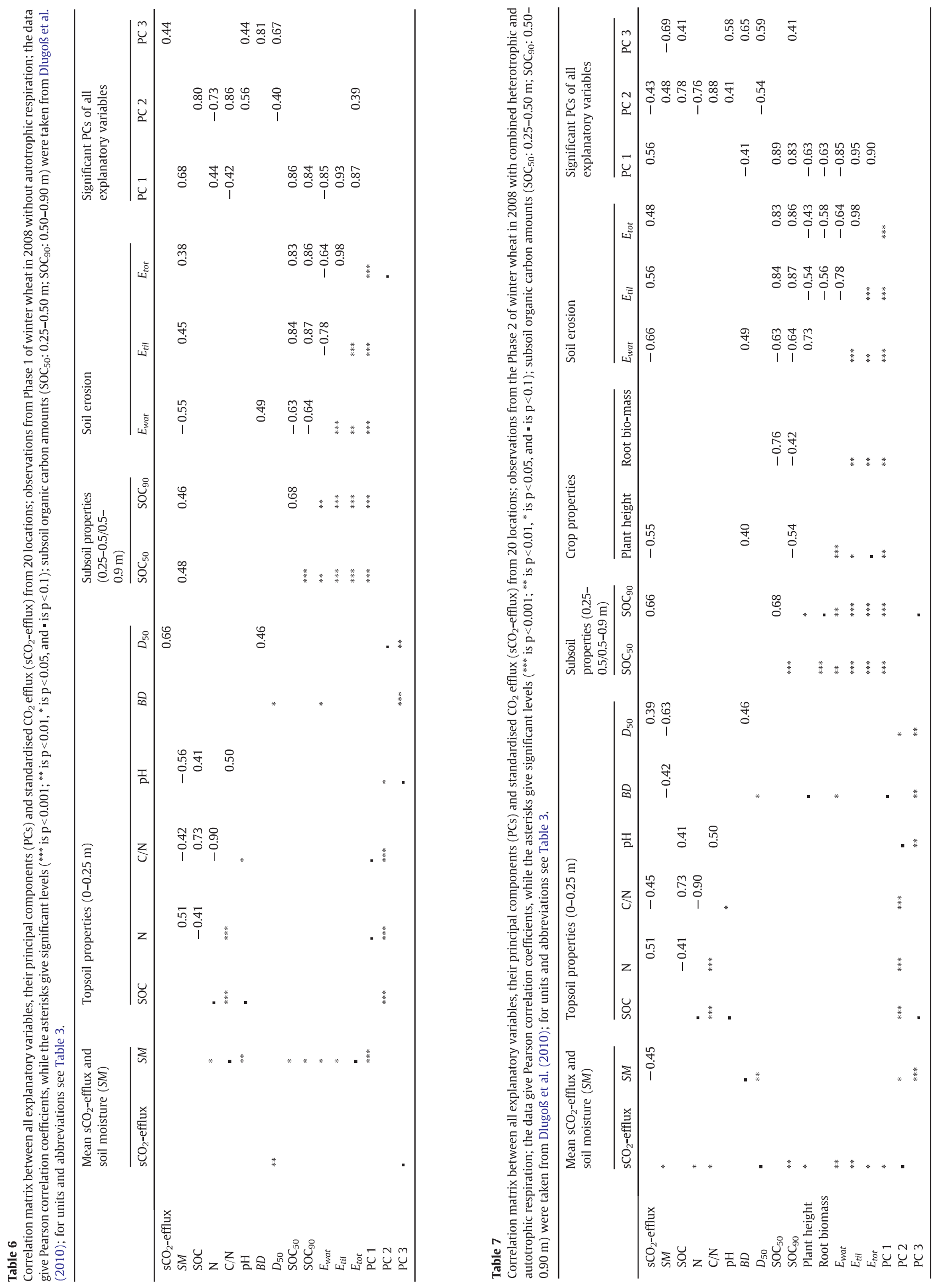


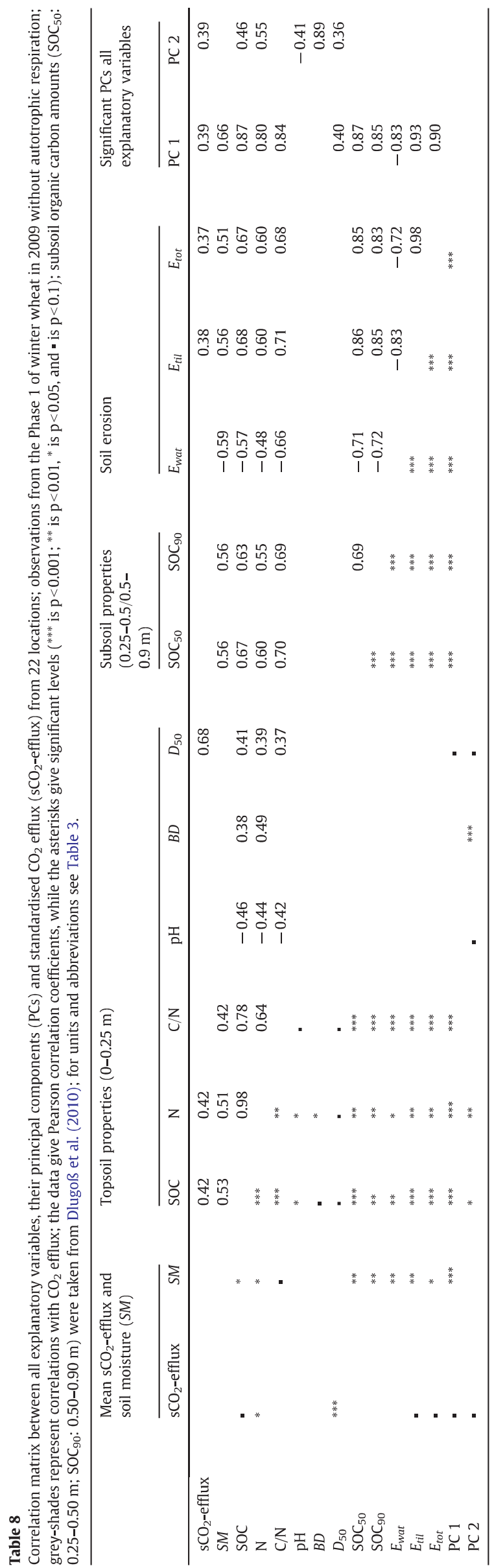

effluxes, at least shortly after deposition events (Van Hemelryck et al., 2010a, 2010b). However, in our study the latter could be neglected, as deposition was impossible within the collars installed at the beginning of the growing period. It must be further noted that the effects of selective transport and deposition by water erosion should be comparably small at our test site, where erosion and deposition are dominated by tillage erosion (Table 1 ).

Besides the potential direct effects of $\mathrm{SOC}$ redistribution on $\mathrm{CO}_{2}$ effluxes, there are also indirect effects on crop growth, which could especially affect autotrophic respiration during the second phase in winter wheat years. According to Berhe et al. (2007), net primary production at depositional sites may increase as a consequence of deposition of organic matter and nutrient-rich topsoil and a corresponding increase in soil water holding capacity. Considering changes in nutrient status, $\mathrm{N}$, and soil moisture, there is some indication that depositional areas provide better growing conditions in some of the measuring phases (2007 and 2009; Tables 4, 8, and 9). However, there was no significant increase in crop growth at the depositional sites from the measured plant height and biomass. Only in Phase 2 of 2008 was there a significant correlation between erosion status and root growth, which might to some extent explain the significant difference in respiration. However, this interpretation should be treated with care as root biomass can only be measured with large uncertainties and root growth around the collars was potentially affected by measuring activities.

Soil erosion patterns might be also intercorrelated with other important drivers of soil respiration, of which the most important should be soil temperature and moisture. According to our analysis of standardised soil temperatures at different landscape positions, there were only small and inconsistent differences within the test site, a result supported by findings of other small-scale studies (e.g. Herbst et al., 2009; Kang et al., 2003). Soil temperature only correlated with soil erosion in 2007. Depositional sites were warmer than erosional sites, which could potentially amplify the difference in respiration. However, as we standardised our $\mathrm{CO}_{2}$ efflux measurements, this should be unimportant for the subsequent analysis. Nevertheless, it should be mentioned that the small differences in soil temperature at the different sites could be a result of measuring in a depth of only $3 \mathrm{~cm}$, which might be optimal for relating respiration and temperature (Graf et al., 2008), but suboptimal for analysing spatial variability of respiration.

There was a weak to highly significant positive correlation between $E_{\text {tot }}$ and $S M$ in 2007 and in Phase 2 of 2008 and 2009, while for the phases with root growth under the collars no significant correlation existed. Interestingly, only in 2007 was there a slightly significant positive correlation $(\mathrm{p}<0.1)$ between respiration and soil moisture, indicating that respiration is dryness limited. In contrast, in Phase 2 of both winter wheat years (2008 and 2009) respiration seemed to be wetness limited (Tables 7, 9), which probably indicates that autotrophic respiration is more sensitive to higher soil water contents. This could at least partly dampen/smooth the difference between erosional and depositional sites for combined heterotrophic and autotrophic respiration. However, compared to other studies (e.g. Herbst et al., 2009) which identify soil moisture as the major reason for field-scale spatial variability of soil respiration, it is less important in our study. This relatively minor importance in our data (Figs. 3-5) probably results from missing extremes (very dry or very wet), which have proven to affect respiration in other studies (e.g. Davidson et al. 2000).

These different direct and indirect effects of soil erosion, and the effects of the intercorrelation of the analysed variables with soil erosion, support increasing $\mathrm{CO}_{2}$ effluxes at depositional sites and decreasing $\mathrm{CO}_{2}$ effluxes at erosional sites. However, our data only give tendencies or relatively weak correlations between spatial patterns of erosion and $\mathrm{CO}_{2}$ effluxes. There might be several explanations for these results: (i) despite its validation for the entire catchment (Dlugoß, 


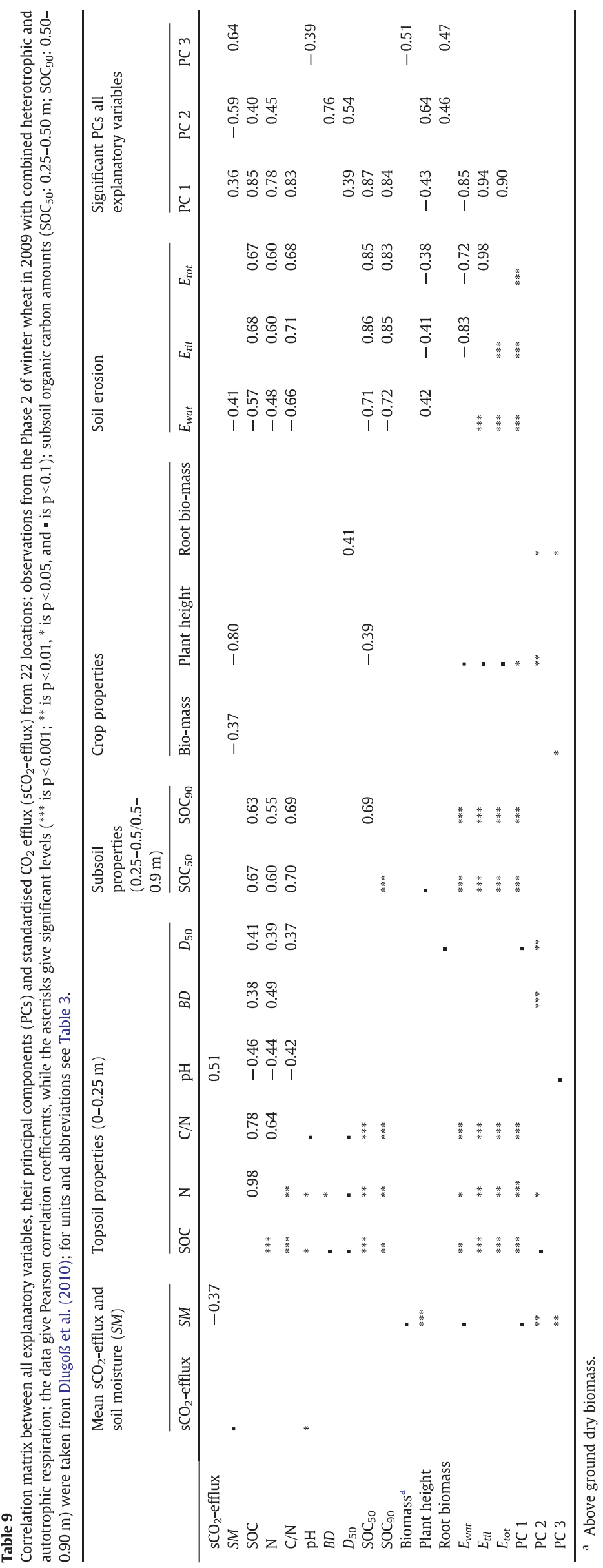




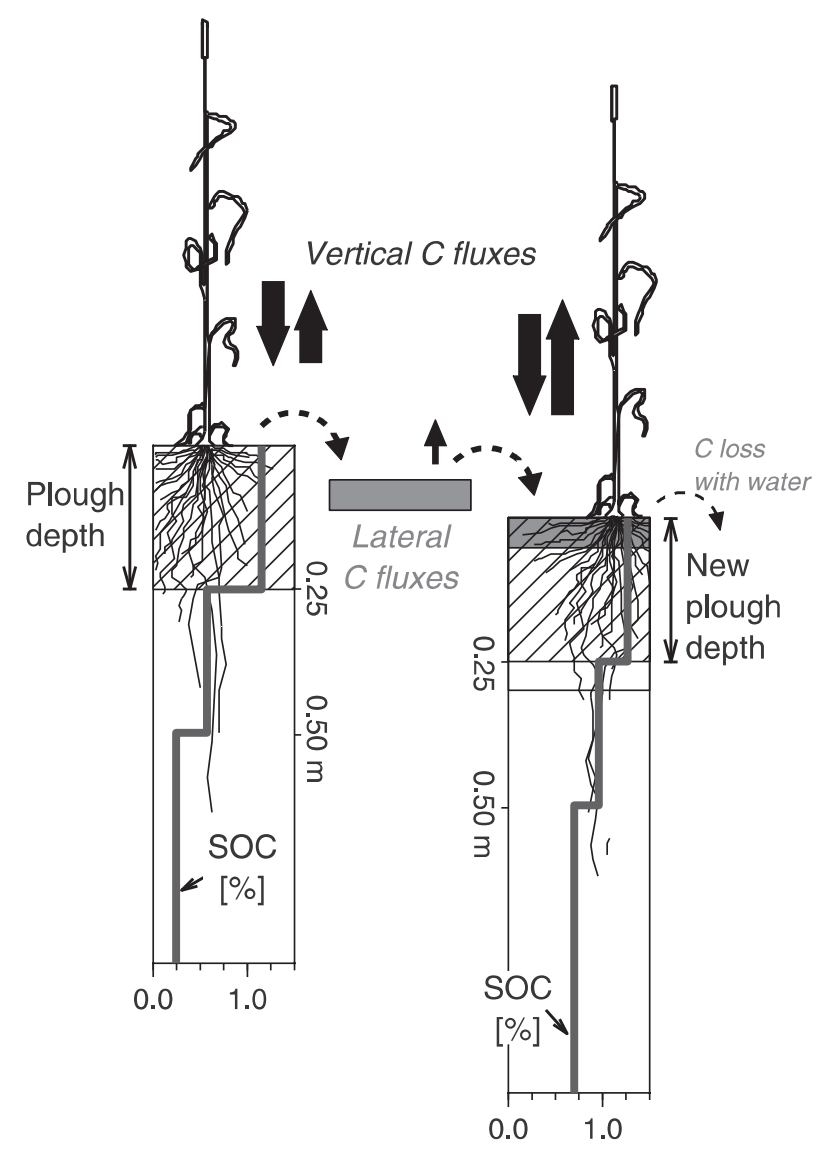

Fig. 7. Schematic representation of carbon fluxes at erosional (left) and depositiona (right) sites; arrows with filled lines show potentially different $\mathrm{CO}_{2}$ fluxes due to carbon sequestration and mineralization as well as potential $\mathrm{CO}_{2}$ loss during soil transport with water; arrows with dashed lines indicate within field lateral $C$ fluxes due to water and tillage erosion as well as $\mathrm{C}$ delivery with water; SOC contents for both profiles represent the mean values of the erosional and depositional sites.

2011), there may still be uncertainties in the modelled soil redistribution rates at the measuring collars. Nevertheless, the model should differentiate well between erosional and depositional sites. Its validity is indirectly supported by the highly significant $(p<0.001)$ correlation

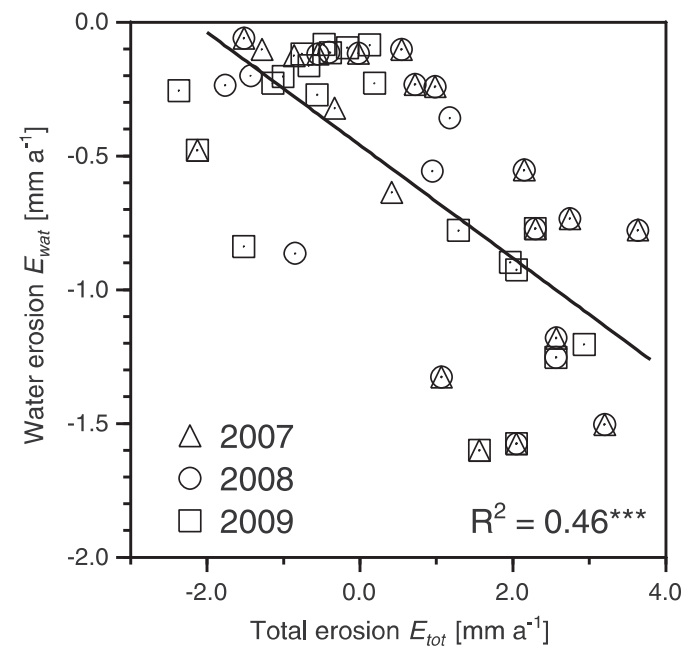

Fig. 8. Water erosion $\left(E_{\text {wat }}\right)$ versus total erosion $\left(E_{\text {tot }}\right)$ (comprising water and tillage erosion) for all measuring locations in 2007, 2008, and 2009, respectively; regression function and $\mathrm{R}^{2}$ are calculated over all years; significance level ${ }^{* * *}$ equals $\mathrm{p}<0.001$. between erosion and subsoil SOC amounts ( $\mathrm{R}^{2}$ between 0.69 and 0.81 ), which should be mainly a result of the redistribution processes. Therefore, we conclude that the modelled erosion rates are good enough for the analysis. (ii) Due to the small-scale variability in soil respiration shown in other studies (e.g. Herbst et al., 2009), more measuring locations representing erosion and deposition would be needed for statistically profound results. (iii) Even after a long cultivation history at our test site, the deep loess-burden soils are not degraded enough to produce a stable spatial variability in soil respiration. However, it is representative of many highly productive loess areas, where yields are kept at consistently high levels due to intensive nutrient supply. If more degraded areas with a substantial variation of $C$ inputs by plants between erosional and depositional sites were analysed, it would be even more difficult to identify other erosion-related parameters for spatial differentiation of soil respiration. (iv) We do not fully understand all the processes associated with SOC redistribution nor all intercorrelations between SOC redistribution and other variables important for $\mathrm{CO}_{2}$ effluxes. Moreover, not all of the processes related to soil erosion and $\mathrm{CO}_{2}$ effluxes described above result in simple spatial patterns which amplify the differences in fluxes at different landscape positions. The most prominent is potentially the overcompensation of water erosion by tillage erosion at our test site, which results in highest total deposition rates in areas of highest water erosion rates (Fig. 8). Hence, areas with a potentially reduced respiration due to the loss of carbon-rich, near-surface soil gain the most SOC via tillage deposition, which smoothes the spatial differentiation in $\mathrm{CO}_{2}$ effluxes between different landscape positions.

\section{Conclusion}

Soil respiration, soil temperature, and soil moisture were measured bi-weekly during three growing periods $(1 \times$ sugar beet, $2 \times$ winter wheat) at 20-22 locations within a small agricultural watershed. The data of the different locations were used to analyse potential effects of soil erosion (modelled with the combined water and tillage erosion model WaTEM-SEDEM) on soil temperature and soil respiration. Moreover, combined effects of erosion and several plant and soil properties were analysed.

A correlation between soil temperature as an important regulator of soil respiration and modelled erosion could only be found in the first measuring year, under sugar beet, when measuring collars were located between plant rows. However, as the mean temperature differences between erosional and depositional sites during single campaigns were small $\left(<1^{\circ} \mathrm{C}\right)$ and somewhat inconsistent, no clear effect on soil respiration can be expected.

After standardising all respiration measurements to remove potential temperature effects introduced by the campaign-type design of our study, it was found that respiration tended to be higher at depositional sites than at erosional sites. An exception was the second measuring phase (combined autotrophic and heterotrophic respiration) in 2009 , when respiration was potentially dominated by increasing root growth under the collars.

The combined analysis of $\mathrm{CO}_{2}$ effluxes, erosion, and other explanatory variables indicates that the spatial variability of median grain size and bulk density had the most consistent effect on the spatial variability of heterotrophic soil respiration (between rows in the case of sugar beet and before significant plant growth in the case of winter wheat). It is interesting to note that soil moisture was less important, although it was often identified as the major driver of the spatial variability of soil respiration in other studies. Moreover, more or less no effect of the spatial variability of topsoil SOC amounts (which was anyway small) on the spatial variability of soil respiration was found. Overall, only in two measuring phases (Phase 22008 and Phase 1 2009) did the combined analysis show that total erosion was one of the dominant variables for the spatial variability of $\mathrm{CO}_{2}$ 
effluxes. In 2008 this effect seemed to be especially related to higher SOC amounts below $0.25 \mathrm{~m}$ at depositional sites.

In general, the relatively inconsistent effect of soil erosion status on spatial variability in $\mathrm{CO}_{2}$ effluxes is somewhat surprising as there are a number of different explanations which support the assumption that $\mathrm{CO}_{2}$ effluxes at erosional sites should be smaller than at depositional sites. A major reason for the observed behaviour might be the compensating effect of tillage and water erosion and the combined/counteracting effects of both processes on soil respiration, which underlines the importance of field-scale studies to gain further insight in the interrelation of soil redistribution and $\mathrm{CO}_{2}$ effluxes.

\section{Acknowledgements}

The study was carried out in the framework of the Deutsche Forschungsgemeinschaft (DFG) project "Soil redistribution in agricultural landscapes - source or sink of $\mathrm{CO}_{2}$ ?" FI 1216/4-1. The assistance with field and laboratory work by Sven Bremenfeld and Martin Parakenings is gratefully acknowledged. Special thanks also go to the farm owner for his permission to carry out the field campaigns and his patience in answering field management questions. Additionally, the financial support of Wolfgang Korres by the SFB/TR 32 "Patterns in SoilVegetation-Atmosphere Systems: Monitoring, Modelling, and Data Assimilation" also funded by the Deutsche Forschungsgemeinschaft (DFG) is gratefully acknowledged. Moreover, we acknowledge the invaluable input of two anonymous reviewers.

\section{References}

Amelung, W., Zech, W., 1999. Minimisation of organic matter disruption during particle-size fractionation of grassland epipedons. Geoderma 92, 73-85.

Bajracharya, R.M., Lal, R., Kimble, J.M., 2000. Diurnal and seasonal $\mathrm{CO}_{2}-\mathrm{C}$ flux from soil as related to erosion phases in central Ohio. Soil Sci. Soc. Am. J. 64, 286-293.

Berhe, A.A., Harte, J., Harden, J.W., Torn, M.S., 2007. The significance of the erosioninduced terrestrial carbon sink. Bioscience 57, 337-346.

Borken, W., Xu, Y.-J., Davidson, E.A., Beese, F., 2002. Site and temporal variation of soil respiration in European beech, Norway spruce, and Scots pine forests. Global Change Biol. 8, 1205-1216.

Davidson, E.A., Verchot, L.V., Henrique Cattanio, J., Ackerman, I.L., Carvalho, J.E.M., 2000. Effects of soil water content on soil respiration in forests and cattle pastures of eastern Amazonia. Biogeochem 48, 53-69.

Davidson, E.A., Janssens, I.A., Luo, Y., 2006. On the variability of respiration in terrestrial ecosystems moving beyond $\mathrm{Q}_{10}$. Global Change Biol. 12, 154-164.

Desmet, P.J.J., Govers, G., 1996. A GIS procedure for automatically calculating the USLE LS factor on topographically complex landscape units. J. Soil Water Conserv. 51, 427-433.

Deutsches Institut für Normung, 2002. DIN ISO 11277: 2002-08 Bodenbeschaffenheit Bestimmung der Partikelgrößenverteilung in Mineralböden - Verfahren mittels Siebung und Sedimentation. Beuth Verlag, Berlin, Germany.

Deutsches Institut für Normung, 2006. DIN ISO 10390: 2005 Bodenbeschaffenheit Bestimmung des pH-Wertes. Beuth Verlag, Berlin, Germany.

Dlugoß, V., 2011. Impacts of soil redistribution processes on soil organic carbon stocks and fluxes in a small agricultural catchment. PhD thesis, Universität zu Köln, Köln, Germany

Dlugoß, V., Fiener, P., Schneider, K., 2010. Layer-specific analysis and spatial prediction of soil organic carbon using terrain attributes and erosion modeling. Soil Sci. Soc. Am. J. 74, 922-935.

Epron, D., Bosc, A., Bonal, D., Freycon, V., 2006. Spatial variation of soil respiration across a topographic gradient in a tropical rain forest in French Guiana. J. Trop. Ecol. 22, 565-574.

Fang, C., Moncrieff, J.B., Gholz, H.L., Kenneth, L.C., 1998. Soil $\mathrm{CO}_{2}$ efflux and its spatial variation in a Florida slash pine plantation. Plant Soil 205, 135-146.

Govers, G., Vandaele, K., Desmet, P., Poesen, J., Bunte, K., 1994. The role of tillage in soil redistribution on hillslopes. Eur. J. Soil Sci. 45, 469-478.

Graf, A., Weihermüller, L., Huisman, J.A., Herbst, M., Bauer, J., Vereecken, H., 2008. Measurement depth effects on the apparent temperature sensitivity of soil respiration in field studies. Biogeosci 5, 1175-1188.

Han, G., Zhou, G., Xu, Z., Yang, Y., Liu, J., Shi, K., 2007. Biotic and abiotic factors controlling the spatial and temporal variation of soil respiration in an agricultural ecosystem. Soil Biol. Biochem. 39, 418-425.

Hanson, P.J., Wullschleger, S.D., Bohlmann, S.A., Todd, D.E., 1993. Seasonal and topographic patterns of forest floor $\mathrm{CO}_{2}$ efflux from an upland oak forest. Tree Physiol. 13, 1-15.
Harden, J.W., Sharpe, J.M., Parton, W.J., Ojima, D.S., Fries, T.L., Huntington, T.G., Dabney, S.M., 1999. Dynamic replacement and loss of soil carbon by eroding cropland. Global Biogeochem. Cycles 13, 885-901

Heckrath, G., Djurhuus, J., Quine, T.A., Van Oost, K., Govers, G., Zhang, Y., 2005. Tillage erosion and its effect on soil properties and crop yield in Denmark. J. Environ. Qual. 34, 312-324.

Herbst, M., Hellebrand, H.J., Bauer, J., Huisman, J.A., Simunek, J., Weihermüller, L., Graf, A., Vanderborght, J., Vereecken, H., 2008. Multi-year heterotrophic soil respiration evaluation of a coupled $\mathrm{CO}_{2}$ transport and carbon turnover model. Ecol. Mod. 214 271-283.

Herbst, M., Prolingheuer, N., Graf, A., Huisman, J.A., Weihermüller, L., Vanderborght, J. 2009. Characterization and understanding of bare soil respiration spatial variability at plot scale. Soil Sci. Soc. Am. J. 8, 762-771.

Kang, S., Kim, S., Oh, S., Lee, D., 2000. Predicting spatial and temporal patterns of soil temperature based on topography, surface cover and air temperature. Forest Ecol. Manage. 136, 173-184.

Kang, S., Doh, S., Lee, D., Lee, D., Jin, V.L., Kimball, J.S., 2003. Topographic and climatic controls on soil respiration in six temperate mixed-hardwood forest-slopes, Korea. Global Change Biol. 9, 1427-1437.

Korres, W., Koyama, C., Fiener, P., Schneider, K., 2010. Analysis of surface soil moisture patterns in agricultural landscapes using Empirical Orthogonal Functions. HESS 14, $751-764$.

Kuhn, N.J., Hoffmann, T., Schwanghart, W., Dotterweich, M., 2009. Agricultural soil erosion and global carbon cycle: controversy over? Earth Surf. Process. Landforms 34, 1033-1038.

Liu, Y., Li, S.Q., Yang, S.J., Hu, W., Chen, X.P., 2010. Diurnal and seasonal soil $\mathrm{CO}_{2}$ flux patterns in spring maize fields on the Loess Plateau, China. Acta Agric. Scand. Sect. B., Soil and Plant Sci. 60, 245-255.

Mabit, L., Bernard, C., Makhlouf, M., Laverdière, M.R., 2008. Spatial variability of erosion and soil organic matter content estimated from ${ }^{137} \mathrm{CS}$ measurements and geostatistics. Geoderma 145, 245-251.

Martin, J.G., Bolstad, P.V., 2009. Variation of soil respiration at three spatial scales components within measured, intra-site variation and patterns on the landscape. Soil Biol. Biochem. 41, 530-543.

Moyano, F.E., 2008. Soil respiration fluxes and controlling factors in temperate fores and cropland ecosystems. PhD thesis, Universität Tübingen, Tübingen, Germany.

Pacific, V.J., McGlynn, B.L., Riveros-Iregui, D.A., Welsch, D.A., Epstein, H.E., 2008. Variability in soil respiration across riparian-hillslope transitions. Biogeochem 91, 51-70.

Papiernik, S.K., Lindstrom, M.J., Schumacher, T.E., Schumacher, J.A., Malo, D.D., Lobb, D.A., 2007. Characterization of soil profiles in a landscape affected by long-term tillage. Soil Tillage Res. 93, 335-345.

Parkin, T.B., Kaspar, T.C., Senwo, Z., Prueger, J.H., Hatfield, J.L., 2005. Relationship of soil respiration to crop and landscape in the Walnut Creek watershed. J. Hydrometeorol. 6, 812-824.

Polyakov, V.O., Lal, R., 2004. Soil erosion and carbon dynamics under simulated rainfall. Soil Sci. 169, 590-599.

Quine, T.A., Van Oost, K., 2007. Quantifying carbon sequestration as a result of soil erosion and deposition: restrospective assessment using caesium-137 and carbon inventories. Global Change Biol. 13, 2610-2625

R Development Core Team, 2007. R: A language and environment for statistical computing. http://www.R-project.org.

Renard, K.G., Foster, G.R., Weesies, G.A., McCool, D.K., Yoder, D.C., 1996. Predicting soil erosion by water: a guide to conservation planning with the Revised Universal Soil Loss Equation (RUSLE). USDA-ARS, Washington DC, USA

Reth, S., Göckede, M., Falge, E., 2005a. $\mathrm{CO}_{2}$ flux from agricultural soil in eastern Germany: comparison of a close chamber system with eddy covariance measurements. Theor. Appl. Climatol. 80, 105-120.

Reth, S., Reichstein, M., Falge, E., 2005b. The effect of soil water content, soil temperature, soil $\mathrm{pH}$-value and the root mass on soil $\mathrm{CO}_{2}$ efflux - a modified model. Plant Soil 268, 21-33.

Rodeghiero, M., Cescatti, A., 2008. Spatial variabilty and optimal sampling strategy of soil respiration. Forest Ecol. Manage. 255, 106-112.

Saiz, G., Green, C., Butterbach-Bahl, K., Kiese, R., Avitabile, V., Farrell, E.P., 2006. Seasonal and spatial variability of soil respiration in four Sitka spruce stands. Plant Soil 287, 161-176.

Schlesinger, W.H., 2005. The global carbon cycle and climate change. Adv. Econ Environ. Resour. 5, 31-53.

Schwendenmann, L., Veldkamp, E., Brenes, T., O'Brien, J.J., Mackensen, J., 2003. Spatial and temporal variation in soil $\mathrm{CO}_{2}$ efflux in an old-growth neotropical rainforest, $\mathrm{La}$ Selva, Costa Rica. Biogeochem 64, 111-128.

Scott-Denton, L.E., Sparks, K.L., Monson, R.K., 2003. Spatial and temporal controls of soil respiration rate in a high-elevation, subalpine forest. Soil Biol. Biochem. 35 525-534.

Shapiro, S.S., Wilk, M.B., 1965. An analysis of variance test for normality (complete samples). Biometrika 52, 591-611.

Shirazi, M.A., Boersma, L., Hart, J.W., 1988. A unifying quantitative analysis of soil texture: improvement of precision and extension of scale. Soil Sci. Soc. Am. J. 52, 190.

Soe, A.R.B., Buchmann, N., 2005. Spatial and temporal variations in soil respiration in relation to stand structure and soil parameters in an unmanaged beech forest. Tree Physiol. 25, 1427-1436.

Stallard, R., 1998. Terrestrial sedimentation and the carbon cycle: coupling weathering and erosion to carbon burial. Global Biogeochem. Cycles 12, 231-257.

Starr, G.C., Lal, R., Malone, R., Hothem, D.L., Owens, L.B., Kimble, J., 2000. Modeling soil carbon transported by water erosion processes. Land Degrad. Dev. 11, 83-91.

Trumbore, S., 2006. Carbon respired by terrestrial ecosystems - recent progress and challenges. Global Change Biol. 141-153. 
Van Hemelryck, H., Fiener, P., Van Oost, K., Govers, G., Merckx, R., 2010a. The effect of soil redistribution on soil organic carbon: an experimental study. Biogeosci 7 3971-3986.

Van Hemelryck, H., Govers, G., Van Oost, K., Merckx, R., 2010b. Evaluating the impact of soil redistribution on the in situ mineralization of soil organic carbon. Earth Surf Process. Landforms. doi:10.1002/esp. 2055.

Van Oost, K., Govers, G., Desmet, P., 2000. Evaluating the effects of changes in landscape structure on soil erosion by water and tillage. Landscape Ecol. 15, 577-589.

Van Oost, K., Quine, T.A., Govers, G., De Gryze, S., Six, J., Harden, J.W., Ritchie, J.C., McCarty, G.W., Heckrath, G., Kosmas, C., Giraldez, J.V., Marques da Silva, J.R. Merckx, R., 2007. The impact of agricultural soil erosion on the global carbon cycle. Science 318, 626-629.
Van Rompaey, A.J.J., Verstraeten, G., Van Oost, K., Govers, G., Poesen, J., 2001. Modelling mean annual sediment yield using a distributed approach. Earth Surf. Process. Landforms 26, 1221-1236.

Verstraeten, G., Van Oost, K., Van Rompaey, A., Poesen, J., Govers, G., 2002. Evaluating an integrated approach to catchment management to reduce soil loss and sediment pollution through modelling. Soil Use Manage. 19, 386-394.

$\mathrm{Xu}, \mathrm{M}$., Qi, Y., 2001. Soil-surface $\mathrm{CO}_{2}$ efflux and its spatial and temporal variations in a young ponderosa pine plantation in northern California. Global Change Biol. 7 667-677. 